\title{
Role of Health Economics Research in Implementing Saudi Arabia's Health Sector Transformation Strategy Under Vision-2030
}

\author{
Kesavan Sreekantan Nair \\ College of Public Health \& Health Informatics, Qassim University, Saudi Arabia
}

\begin{abstract}
Health economics analyses play a crucial role in providing health policy makers and planners with the relevant information required to maximize the use of available resources. Health system reforms introduced in Saudi Arabia have recognized the application of health economic theories in making policy decisions and many of the health system strategies proposed under the Saudi vision-2030 have health economic ramifications. Since the health system has undergone a rapid transition leading to new set of health problems related to non-communicable diseases and life style disorders, the country needs more cost-effective strategies to improve maximum health gains and reduce future financial burden of the government. The paper highlights some reflections on the role and relevance of health economics and health economic research in implementing various strategies proposed under the vision. The paper also provides implications of developing health economics knowledge among physicians and how such knowledge can be applied to evidence based decision making on the use of health resources. It recommends the need for creation of opportunities for development of health economics and integration of health economics discipline into medical education curriculum in Saudi Arabia.
\end{abstract}

Keywords: health economics, health resources, Saudi vision-2030, transformation strategy

DOI: $10.7176 / \mathrm{JESD} / 10-18-12$

Publication date:September $30^{\text {th }} 2019$

\section{Introduction}

One of the major objectives of health system in most countries is to improve the health of population with the efficient use of available resources. With the increasing life expectancy at birth, raising ageing population and increasing prevalence of non-communicable diseases, health systems in most countries are facing the challenges of providing equitable access to quality health services as proclaimed in their constitutions (WHO, 2001; Ke X, Saksenaa P, Holly A, 2011). Economic slowdown in several countries has further compelled health policy makers to make use of available resources in more efficient ways. Health economics, a specialized discipline which applies economic concepts, theories, models, and approaches to health and health care inter alia aims to maximize the health of population by using available scarce resources (WHO, 2001). Economic analyses have been widely used in the health systems of advanced economies countries and it plays a significant role in the development of health policies, planning, programs and health interventions by optimal use of available resources.

Economic evaluation plays a critical role in setting priorities in health care decision making and different techniques of evaluation are applied to assist the optimal allocation of scarce health resources and to maximize the health of the society (Drummond et al, 1987). There has been limited application of economic evaluation in health care programs in low income countries, probably due to factors that might limit the use of economic principles including barriers in production of economic data for conducting such evaluation (Vieira, 2016). In order to make well-informed decisions about the best use of health care resources, policymakers, health administrators and users of health care services must have adequate information on both the costs and benefits associated with the decisions. Saudi Arabia is committed to utilizing available resources most efficiently and reducing wastages in use of health resources. Series of reforms introduced in Saudi Arabia's health system have emphasized the role and application of health economic theories and approaches in making policy decisions. Within this context, this paper aims to provide some reflection on the role and relevance of health economics and health economic research in managing national health systems with special reference to Saudi Arabia.

\section{Saudi Arabia's Health System}

\subsection{Health Services Delivery}

Saudi Arabia, an economy endowed with rich oil resources, has been offering free health care services to citizens as stipulated in its constitution. Since the beginning of economic development plans, the country has emphasized the role of population's health as one of its priority areas, and its commitment to health sector is reflected in increased allocation of national budget to health care and rapid expansion of health care delivery system, resulting in overall improvement in health status of population $(\mathrm{MOH}, 2017)$. Health care in Saudi Arabia is predominantly public funded via the Ministry of Health $(\mathrm{MOH})$, which provides about $60 \%$ of health care services in the country through its network of 282 hospitals with 43080 beds and 2631 primary health centers, while other government 
agencies together operate 47 hospitals (12279 beds). The private health sector owns 158 hospitals (17 622 beds), 2767 general/specialized polyclinics, and 61 clinics across the country (MOH, 2017). MOH plays an integral role in planning, managing, implementing, promoting, and evaluating the provision of health services across the country (Kaliq, 2012). It coordinates with other governmental agencies and monitors, advises, evaluates and supports the private health sector in all health care programs or activities through its regional directorate (AlHanawi et al, 2018a).

\subsection{Health System Reforms}

Public sector funding has mostly been dependent on revenue from oil exports. Despite increase in level of public spending, it has been increasing challenge for the government to continue with the provision of free health care services to its population. The country has been facing many health system challenges such as demographic transition, changing diseases patterns, increasing life expectancies, and rising health care costs (Al Hanawi et al, 2018a). Thus the health system is under strain as a result of rapid increase in demand for quality health services and uncertainties regarding oil prices in international markets. This situation led the government to consider alternate source of funding health care, a shift away from the traditional welfare approach to involving the private sector to share the responsibility along with the public sector (Al-Hanawi and Qattan, 2019; Rehman and Alsharqi, 2019).

The government has implemented series of health reform initiatives to provide access to best quality health care to its citizens through efficient utilization of resources. As a part of administrative reform in the health system, the government created the Council of Health Services (CHS) in 2002 to improve coordination and communication among health services providers in the country. It also created 20 regional health directorates across the country to oversee regional hospitals and primary health centers (Al-Yousif et al, 2002). In 2005, Saudi Central Board for Accreditation of Health Institutions (SCBAHI) was established with the objective to develop national standards for delivery of health care and improving safety and quality of health care (Alkhenizan and Shaw, 2011; Almalki et al, 2011). The government has taken initiatives to establish new medical cities, expansion of existing medical cities including establishment of new hospitals and health centers. In order to encourage the private sector investment in health care, the government invited the foreign as well as the Saudi nationals by offering economic incentives. The cooperative health insurance act of 2003 and establishment of Council of Cooperative Health Insurance $(\mathrm{CCHI})$ were the major step towards insurance reform. Under this reform, all workers employed in the private sector should be insured by their employers by paying insurance premiums (Almalki et al, 2011; Al-Hanawi and Qattan, 2019).

Vision-2030 announced by the government in April 2016, aimed at transforming the economy and reducing its dependence on oil revenue (KSA, 2016a). The vision is based on three major themes of a vibrant society, a thriving economy, and an ambitious nation. In order to assess the progress of vision, the National Transformation Program (NTP) - 2020 was launched in June 2016 across various economic sectors (KSA, 2016b). NTP laid down many objectives in health sector, key focus areas of which include increasing private health care spending from $25 \%$ to $35 \%$ of total health spending by 2020 , Both the vision and the NTP indicates a paradigm shift in Saudi Arabia's health system from its welfare oriented approach.

\section{Health Economics for Managing Health System}

A country's economic development is greatly influenced by health status of its population, which depends on level of health services and other non-health related services provided to the population. Development of health policy and its implementation are influenced by macro- economic considerations. Planning for health services essentially based on the principles of choice, which is one of the basic concepts in economics. Several authors established through their contributions the potential role of health economics for management of health systems. Mooney and Drummond (1982a \& 1982b) through their series of papers highlighted various economic issues based on analysis of the National Health System (NHA) in the United Kingdom. They showed how the health system goals can be achieved in best possible ways using available scarce resources. The authors tried to demystify health care professionals understanding about health economics by explaining the concepts of choice and opportunity costs and clarified that maximizing the health care benefits with improved efficiency is an end to itself and not minimizing cost. Health care benefits are valued using the concept of opportunity costs and resource allocation decisions for health interventions whose benefits outweighed its costs are preferred (McIntosh and Fernandez, 2006; Drummond et al, 2005; Graham, 2003).

Funding health care itself is a basic economic decision which all governments need to make as its funding deals with a complex relationship involving health services providers, patients, health care organizations, health insurance companies and the community. The appropriate funding mechanism links the needs of patients (improved health) with the services provided by health care organizations (health care). There are possibilities of overutilization of health care services by individuals if they need not to pay for extra care which adversely affects the use of care by other members of the community. Similarly different mechanisms of funding and organizing 
the delivery of health care services may influence provider's behavior through incentives and barriers which can be a fundamental measure to achieve efficiency in health system. Economics principles and approaches can be used to support health policy development, planning for health services, measurement of health status and value of health, economic burden of diseases, apart from evaluation of costs and benefits of alternate health interventions (Mooney and Drummond, 1982c). Health economics tools can be used to establish priorities in health policies studying the relationship between different sectors influencing health of population. Economic evaluation techniques can be used in planning health services at national level, for planning a new hospital or strengthening of existing health facilities. These techniques can be used to support decision making for development of local health services or interventions. Institutionalizing National health accounts and its applications in health policy development, is another emerging area where health economists' contributions are imminent. Thus, health economics provides a wide ranging approach to improve the utilization of scarce resources through reduction in future disease burden and improve the health status of population in countries that are facing resource crunch and increasing population with enormous health care needs.

However, there are many challenges in the application of economic principles in health systems in some countries which range from nature of decision making process at the central level, lack of application of economic evaluation studies on alternate interventions, lack of health economic expertise, cultural and political contexts in which major decisions are taken in the health systems (Mills A, 2014). There are certain methodological issues involved in applying health economics to public health (Dang et al, 2016). In developed countries, health economics as a discipline was stimulated by the increasing academic interest in economic aspects of public health policies leading increased research funding, but in developing countries, studies have found that lack of experience, deficiency in funding, inappropriate use of tools, and lack of academic interest in the subject were pointed out as obstacles for use of health economics (Vieira, 2016). However, use of economic analysis in health care at the global level has been promoted by the World Health Organization, multilateral and bilateral agencies which led to expansion of its interest in middle and low income countries.

One of the learning objectives of public health education is that a professional in public health should acquire the knowledge and skills required to perform as an effective leader at community level. In order to ensure efficient, effective and equitable health care, it is necessary to have a sound understanding of principles and approaches of economics applied to health care (Goeree and Diaby, 2013). The concept of efficiency refers to how well resources are utilized to provide given health services. By using available resources in efficient manner the services would not only benefit the individual, but the whole society. Effectiveness refers to the extent to which the specified health problem is cured or reduced. Equity concept explains fairness in the distribution of health resources among population groups. Redistribution of resources like health infrastructure, equipment, physicians, and nurses is done to overcome unequal access to health services across geographic regions or population groups.

Economic evaluation provides a comparative analysis of alternative course of action in terms of both their costs and consequences of any health intervention (Drummond, et al., 1997; Drummond et al, 2005). Economic evaluation has two features. It is a comparative analysis, and compares two or more different options; and it compares these options in terms of their costs and consequences. Cost minimization analysis (CMA) is a narrow concept and is used in situation where benefits of alternative interventions or treatment have been considered to be identical. CMA is used to measure and compare the monetary value of resources (i.e. input costs) across alternatives where the outcomes are identical. Cost benefit analysis (CBA) is a technique of economic evaluation where the monetary value of the resources used by a health intervention is compared with the monetary value of the health outcomes ie., benefits achieved by the intervention (Graham, 2003). Cost-effectiveness analysis (CEA) is the most commonly used approach of economic evaluation in health sector, which measures the value of resources spent on an intervention (measured in money terms), are compared to the consequences in the physical units of effectiveness that are natural to the intervention. CEA compares both the cost of an intervention with health outcomes of the intervention. It is typically expressed as cost effectiveness ratio (CER) which is a ratio of costs divided by health outcomes. Cost Utility Analysis (CUA) is a wider form of economic evaluation technique in which the consequences are generally measured in quality-adjusted life years (QALYs), which attempt to capture and reflect both the quantity of life years added by a health care intervention and the quality of life resulting from intervention (Phillips, 2005; Bidgoli et al, 2014). In public health arena, CEA can be used to compare effectiveness of different public health strategies, which has proved to be an effective tool in decision making of health programs at community level in most countries (Nair et al, 2017). Physicians can play a key role in cost containment through preventing wastages, reducing use of unnecessary drugs, prescription of cheaper alternatives and optimal use of staff hours (Goeree and Diaby, 2013).

\section{Policy implications for Saudi Health System}

\subsection{Role of Health Economics Tools in Policy Implementation}

The crux of Saudi Arabia's National Healthcare Transformation Strategy (NHTS) is based on economic theories (KSA, 2016c). Most of the health system challenges are proposed to be addressed by the NHTS have health 
economic ramifications. NHTS identified eight major challenges in Saudi health care system that needs to be addressed on priority basis. These are (i) the growing population including increase in elderly population. It is expected that population in Saudi Arabia will reach from 33.5 million in mid-2018 to 39.5 million by mid-2030. The number of elderly persons is likely to increase from 1.96 million in 2018 to 4.63 in 2030. (ii) increasing number non-communicable diseases like cancers, diabetes, heart diseases and other congenial diseases. (iii) inadequate and inconsistent primary health care including long term and home care and its distribution across different regions in the country. (iv) gaps in quality of services delivered to patients with regard to application of protocols for treatment, process and outcome of treatment. (v) variation in availability, accessibility and utilization of health services across different regions. (vi) resource and workforce centric rather than patient centric system.(vii) gaps in health workforce expertise and capability, particularly among Saudi nationals and (viii) containment of future public health expenditures. In order to address these challenges, the NHTS adopted three goals, which are consistent with the value based health care frameworks viz; (i) increase the length, wellbeing and quality of life of Saudi citizens. (ii) improving the quality and consistency of services and the performance and accountability of healthcare organizations and workforce to deliver safe, effective, patient-centered, timely and equitable care and (iii) cost containment, improved outcomes, controlling public healthcare expenditure and guiding new allocations.

NHTS goals reflect the financial, economic and institutional frameworks as well as the policy intentions of the government aiming at overall reduction in public health spending and rational use of available resources. As depicted in Table1, these goals will be accomplished through new models of care, health care provider reforms, financial reforms, governance development, private sector participation, capacity building of health workforce and e-health system.

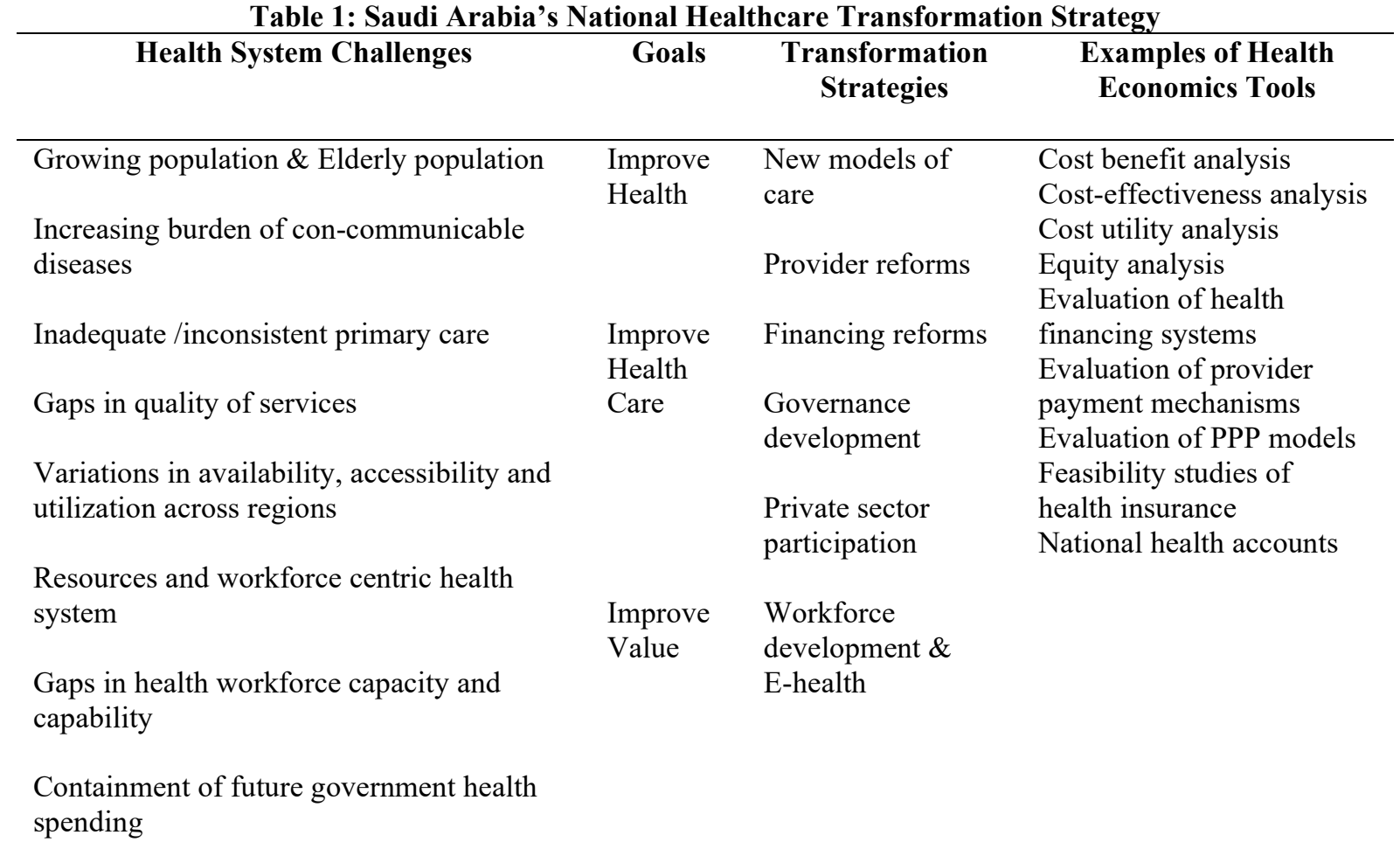

Saudi Arabia's health system need to establish priorities, adopt efficiency measures and undertake economic evaluation of health care programs. Overall objective of strengthening the health system requires taking optimal decision to yield the best value from the available resources. Therefore health economics researches can provide information related to extent of achievement of each strategic goal. Improvement in health status may be measured by applying a set of country-defined key indicators by the World Health Organization (WHO). Wherever prioritization of health interventions are involved, the techniques like Disability Adjusted Lifer Years (DALYs) and Quality Adjusted Life Years (QALY's) using cost-utility analysis may be adopted (Mann et al, 2011). While DALYs measure the number of healthy life lost due to ill health, death and disability across a population, QALYs indicate how many years of healthy life may be gained as a result of a health intervention. Many times health outcomes by themselves may not be sufficient to assess the benefits derived from a health system, because the system can achieve better health outcome, even without providing services to those in greater need. There is therefore a need for assessment of equity of access to health service delivery across population including the level of social and financial risk protection. 


\subsection{Contribution of Health Economics Research}

Saudi Arabia requires researches in several economic aspects of health care system, which can contribute to health policy decision making. These researches may help in identifying weaknesses in the health system and various causes at operational, strategic and programmatic levels. With the increasing share of ageing population, raising burden of non-communicable diseases, use of modern technology and expensive cost of treatment, the country's health care costs are expected to increase in near future which tempted government to seek alternative health financing mechanisms. In this context in-depth economic analysis investigating the outcomes of the various financing mechanisms in achieving efficiency, quality and equity need to be explored. Further, efficiency studies may be undertaken to assess whether the available resources are being utilized in the most productive ways. Efficiency of health service provision can be assessed in terms of allocative or technical efficiency. While allocative efficiency gives information on which services should be provided and at which levels of the health system, technical efficiency gives the guidance on mix of inputs that could be utilized to provide those health services. Health insurance companies in Saudi Arabia may use economic evidence to justify their growth objectives through minimization of hospitalization days or minimization of hospital expenses of the insured population. Many health insurance companies follow primary prevention or health promotion as one of the strategies for cost reduction. Feasibility studies on implementing a national health insurance system, evaluation of different types of provider payment mechanisms, Studies and surveys for development of national health accounts can also be undertaken.

Evidence related to cost data can be used to inform the policy makers which can answer allocative questions related to allocative efficiencies across various strategies for prevention. The government in its perspectives looks at costs and benefits across various investments primarily on healthy living and the economic impact of improved health status. Health economics research can contribute to the implementation of PPP strategies under vision-2030 and NTP-2020. Economic analyses on the trends and dynamics of financing PPP initiatives in comparable countries, experiences of different PPP models in achieving efficiency, quality and equity and value for money, other economic consequences, cost comparisons of PPP versus non-PPP models, macro impacts of PPP initiatives successfully undertaken in countries which share similar socio, economic, political and cultural milieu can provide more insights to policy makers.

As Saudi Arabia's health system has undergone a rapid transition leading to new set of health problems related to non-communicable diseases and life style disorders including mental health challenges, which requires introduction of cost effective strategies for health promotion strategies, disease prevention, and health communication. These strategies are expected to reduce future cost of treatment and improve future productivity. Diseases burden studies including both direct and indirect costs associated with the treatment of diseases can be carried out. While direct costs include cost of administration, drugs cost, clinical training program, research, infrastructural development etc., indirect costs may include transport expenses, absenteeism and loss of productivity due to disease, unemployment due to early mortality by disease.

In the past, there were some attempts to conduct economic evaluations of health programs in Saudi Arabia, but majority of these studies suffered from flaws in in terms of study design, data analysis, and reporting of the outcomes, lack of perspectives for analysis and inappropriate methodology for collecting outcome and cost data, (Al Aqeel SA, 2012). This shows the need for building economic evaluation capacity to enable future economic evaluations for priority settings in the kingdom. Recently, several attempts have also been made to conduct researches in specific areas of health economics which include public private partnership in health care (Alonazi, 2017; Al-Hanawi and Qattan,2019), health workforce development (Albejaidi and Nair, 2019), financing reforms in health care (Al-Hanawi, 2017; Al-Hanawi et al, 2018a; Al-Hanawi et al 2018b) economic model of ischemic stroke care development (Al-Senani et al, 2019), economic costs of diabetics (Al-Howaish, 2013), public hospital efficiency (Al-Atawi et al, 2019).

\section{Need for Integration of Health Economics into Medical Curriculum}

In Saudi Arabia, several past studies postulated the need for training in health economics to physicians and medical graduates, but there has been limited attempt to integrate health economics discipline into medical curriculum (Daar and Al-Shehri, 2015). Unlike in advance countries, where physicians can exert evidence based influence on use of health care resources, the importance of the requirements of economics knowledge alongside clinical practice is not well recognized in Saudi Arabia. In order to have an understanding of various economic consequences of clinical decisions and how such decisions address the challenges of the health system, there is an urgent need to integrate health economics discipline into clinical practice. In the era of raising health care costs, physicians should be conscious of economic consequences of their professional decisions, and they should be equipped with necessary skills to undertake economic evaluation of new health interventions, particularly when health care costs are increasing (Goeree and Diaby, 2013).

In the context of Saudi Arabia, as majority of population receive free care, they are not tempted by key economic issues like raising costs and prices, however these issues have key implications for the overall resource 
allocation by the government. An integrated curriculum can provide the medical students with the key concepts in health economics, and analytical techniques for health planning and management. By integrating economics in to clinical practice, physicians can ensure the practice of efficient medicine based on evidence for the benefit of entire citizen. They should also have the knowledge of integrating costs in to standard treatment guidelines and evidence based decision making as these take into account raising health care costs. This would not only improve health outcomes of population and quality of care, but also lead to efficient use of health resources (Daar and Al-Shehri, 2015). It can also enable physicians to evaluate economic value of alternative interventions in terms of cost savings, cost effective or any other aspects that can help make informed decision (Nath, 2008).

Besides, the physicians should also develop knowledge of macroeconomic issues like how health system allocate scare resources to produce and distribute health goods and services; and what influence the decision to allocate resources, what mix of resources like health infrastructure, physicians, nurses, drugs and equipment are required for each health facility etc. At policy making level, one needs to understand the macroeconomic environment in which health system in Saudi Arabia operates. The officials involved in policy making need to acquire in-depth understanding of macroeconomic concepts and theories and factors that affect health care sector like rising cost of health care, increasing prices of health goods and services. Considering the significance of health economics research in all these spheres, there is a need to build capacities within the system.

\section{Conclusion}

Health economics applies economic concepts, theories, models, and approaches to health and health care inter alia aims to maximize the health of population by using available scarce resources. Health policy development and its implementation are largely influenced by both micro and macro-economic considerations. Health economics analyses play an integral role in the implementation of various strategies proposed under the Saudi Arabia's vision2030. Since the country's health system has undergone a rapid transition leading to new challenges, more cost effective strategies are required to improve maximum health gains and reduce future cost of treatment. Research in several economic aspects of health care system can provide valuable information for health policy makers.

The government needs to create opportunities for development of health economics discipline and promote health economic research within the country to generate system relevant information including efficiency, equity and quality of care. It is argued that physicians' knowledge of health economics tools can benefit them in clinical practice and their skills in application of these tools can assist them to achieve improved outcomes with best use of resources. It is imperative that Saudi Arabia initiate effort to develop knowledge of physicians in using economic tools in decision making. Hence it is high time for medical education system in Saudi Arabia to initiate necessary steps for integration of health economics discipline into medical education curriculum.

\section{References}

1. Al-Aqeel, SA. (2012) State of health economic evaluation research in Saudi Arabia: A review, Clinico Economics and Outcomes Research, 4(1): 177-184.

2. Al-Atawi, A., Ahmed, S., Niessen, L. and Khan, J. (2019) Systematic review and meta-analysis of public hospital efficiency studies in Gulf region and selected countries in similar settings, Cost Effectiveness and Resouce Allocation, 17(17):1-12, available: https://doi.org/10.1186/s12962-019- 0185-4 [accessed 10 July 2019].

3. Albejaidi, F. and Nair, KS. (2019) Building the health workforce: Saudi Arabia's challenges in achieving Vision 2030, International Journal of Health Planning and Management, 1-12, available:https://doi.org/10.1002/hpm.2861 [accessed 12 August 2019].

4. Al-Hanawi, MK. and Qattan, AMN. (2019) An analysis of public-private partnerships and sustainable health care provision in the Kingdom of Saudi Arabia, Health Services Insights, 12:1-10.

5. Al-Hanawi. M.K., Alsharqi1, O., Almazrou S. and Vaidya, K. (2018a) Healthcare finance in the Kingdom of Saudi Arabia: A qualitative study of householders' attitudes, Applied Health Economics and Health Policy, 16:55-64, available: https://doi.org/10.1007/s40258-017-0353-7. [accessed 18 August 2019].

6. Al-Hanawi, M.K., Vaidya, K., Alsharqi1, O., Onwujekwe, O. (2018b) Investigating the willingness to pay for a contributory national health insurance scheme in Saudi Arabia: A cross-sectional stated preference approach, Applied Health Economics and Health Policy, 16:259-271, available: https://doi.org/10.1007/s40258-0170366-2.[accessed 23 July 2019].

7. Al-Hanawi, M.K. (2017) The healthcare system in Saudi Arabia: How can we best move forward with funding to protect equitable and accessible care for all?, International Journal of Healthcare, 3(2): 78-94, available: https://doi.org/10.5430/ijh.v3n2p78.[accessed 19 July 2019].

8. Alhowaish, AK. (2013) Economic costs of diabetes in Saudi Arabia. Journal of Family and Community Medicine, 20(1):1-7.

9. Alkhenizan, A. and Shaw, C. (2011) Impact of accreditation on the quality of healthcare services: a systematic review of the literature, Annals of Saudi Medicine, 31:407-16. 
10. Almalki, M., FitzGerald, G. and Clark, M. (2011) Health care system in Saudi Arabia: an overview. Eastern Mediterranean Health Journal. 17:784-93.

11. Alonzi, WB. (2017) Exploring shared risks through public private partnerships in public health programs: a mixed method, BMC Public Health, 17.571, DOI 10.11861s12889-017-4489-z.

12. Al-Senani, F., Al-Johani, M., Salawati, M. et al. (2019) A national economic and clinical model for ischemic stroke care development in Saudi Arabia: A call for change. International Journal of Stroke, 0(0) 1-8. DOI: $10.1177 / 1747493019851284$.

13. Al-Yousuf, M., Akerele, T. and Al-Mazrou, Y. (2002) Organization of the Saudi health system. Eastern Mediterranean Health Journal, 8(4):645-653.

14. Bidgoli, HH., Kiadaliri, AA. and Worrall, JS. (2014) Do economic evaluation studies inform effective healthcare resource allocation in Iran? A critical review of the literature, Cost Effectiveness and Resource Allocation, 12:15, available: http://www.resource-allocation.com /content/12/1/15. [accessed on 15 July 2019].

15. Daar, OB. Al-Shehri, AM. (2015) Towards integration of health economics into medical education and clinical practice in Saudi Arabia. Economics and clinical practice, 37:sup1, S56-S60, available https://doi.org/10.3109/0142159X.2015.1006611. [accessed on 14 August 2019].

16. Dang, A., Likhar, N., Alok, U. (2016) Importance of economic evaluation in health care: an Indian perspective, Value in Health Regional Issues, 9C 2016; 78-83, available: http://dx.doi.org/10.1016/ j.vhri.2015.11.005. [accessed on 12 August 2019.

17. Drummond, MF., O'Brien, B., Stoddart, GL. and Torrance GW. (2005) Methods for the economic evaluation of health programmes. 3rd edition. New York: Oxford University Press.

18. Drummond, MF., Stoddard, GL. Torrance, W. (1987) Methods for the Economic Evaluation of Health Care Programmes. Oxford, UK: Oxford University Press.

19. Goeree, R. and Diaby, V. (2013) Introduction to health economics and decision-making: Is economics relevant for the frontline clinician?, Best Practice \& Research: Clinical Gastroenterology, 27(6):831-844. DOI: 10.1016/j.bpg.2013.08.016.

20. Graham, JD. (2003) Costs benefit analysis in health policy, Value in Health, 6(4):417-9.

21. Ke, X., Saksenaa, P. and Holly, A. (2011) The determinants of health expenditure: a country-level panel data analysis, Working Paper. Geneva: World Health Organization, available: http://www.who.int/health_financing/documents/report_en_11_deter-he.pdf. [accessed 25 July 2019].

22. Khaliq, AA. (2012) The Saudi health care system: a view from the minaret, World Health Popul, 13(3):5264.

23. Kingdom of Saudi Arabia. (2016a) Saudi Arabia's Vision 2030, available: $\mathrm{http} / / \mathrm{www} . v 0 s i o n 2030$. gov.sa/en/ntp. [accessed July 14, 2019].

24. Kingdom of Saudi Arabia. (2016b) Saudi Arabia's National Transformation Program, available: https://vision2030.gov.sa/sites/default/ files/NTP_En.pdf. [accessed July 14, 2019].

25. Kingdom of Saudi Arabia. (2016c) Health sector transformation strategy, available: https://www.moh.gov.sa/en/Ministry/vro/Documents/Healthcare-Transformation-Strategy.pdf. [accessed July 04, 2019].

26. Mann, GH., Thomson, R. and Jin, C. et al. (2011) The role of health economics research in implementation research for health systems strengthening, International Journal of Tuberculosis \& Lung Diseases, 15(6):715721. DOI:10.5588/ijtld.10.0749.

27. McIntosh, E. and Fernandez, RL. (2006) Economic evaluation. Part 1: Introduction to the concepts of economic evaluation in health care, Journal of Family Planning \& Reproductive Health Care, 32(2):107-112.

28. Mills, A. (2014) Reflections on the development of health economics in low- and middle-income countries, Proceedings of the Royal Society B, London, 281(1789), available: https://www.ncbi.nlm.nih.gov/pmc/articles/PMC4100502/. [accessed 7 July 2019].

29. Ministry of Health. (2018) Statistical Yearbook 2017, Riyadh: Ministry of Health, Kingdom of Saudi Arabia.

30. Mooney, GH. and Drummond, MF. (1982a) Essentials of health economics. Part I - What is economics? British Medical Journal, 285(6346): 949-950.

31. Mooney, G H. and Drummond, MF. (1982b) Essentials of health economics. Part I (continued) - What is economics? British Medical Journal, 285(6347):1024-1025.

32. Mooney, GH and Drummond, MF.(1982c) Essentials of health economics. Part III -Developing health care policies. British Medical Journal, 285(6350): 1263-1264.

33. Nair KS., Jehan, M., Albejaidi F. and Pasha, SA. (2017) Cost-effectiveness analysis for decision making in health care-concept, relevance and methodological challenges, International Journal of Community Medicine \&Public Health, 4:2212-8.

34. Nath, A.(2008) Health Economics: Importance for public health in India, JK Science, 10(4):206-207.

35. Phillips, CJ. (2005) Health Economics - An introduction for health professionals. 1st edition. Oxford: 
Blackwell publishing.

36. Rehman, R. and Alsharqi, OZ. (2019) What drove the health system reforms in the Kingdom of Saudi Arabia? an analysis, International Journal of Health Planning \& Management, 34:100-110. DOI: 10.1002/hpm.2584.

37. Vieira, FS. (2016) Reflections on the role of health economics units regarding national health care systems, Saude Soc, 25(2) :1-12, available :http://dx.doi.org/10.1590/S0104-12902016154831. [accessed 3 July 2019].

38. World Health Organization. (2001) Macroeconomics and Health: Report of the Commission on Macroeconomics and Health, Geneva, available at: who/int/iris/bitstream/ 10665/424251/ 924154550X.pdf. [accessed 11 March 2019]. 